\title{
Factors Affecting the Adoption of Digital Payment Systems
}

\author{
Sushant Raj Giri ${ }^{*}$, and Subodh Kumar Ghimire ${ }^{2}$ \\ ${ }^{1}$ Department of Industrial Engineering, Thapathali Campus, Institute of Engineering, \\ Tribhuvan University, Kathmandu, Nepal \\ ${ }^{2}$ Department of Automobile and Mechanical Engineering, Thapathali Campus, Institute of Engineering, \\ Tribhuvan University, Kathmandu, Nepal \\ "Corresponding Email: sushantgiri@ioe.edu.np
}

\begin{abstract}
Payment for goods and services in Nepal is characterized by long queues; long distance traveling and time wasting that generally affect business activities and ultimately economic development. Settling utility bills, payment for goods and services, and money transfers has been a major headache for individual and firms in Nepal resulting in declined business activities and huge debt to most of the utility providers. In fact, the country have not yet realize the full benefits of the technological advances in electronic payment such as the use of cards, automated teller machines (ATM), the Internet, mobile phones, and other devices. To identify factors that influence the acceptance of these payment systems a theoretical extension of the Technology Acceptance Model, Theory of Planned Behaviour and Trust was used to evaluate the factors that influence the adoption and acceptance of the information technology and system of Internet; in the e-Finance sector in Nepal, especially in digital transaction services. This study will address the questions about the factors that affect the adoption of digital transaction services and the extent these factors affect people's intention towards the adoption of those services.
\end{abstract}

Keywords: Digital Transaction, e-Payments, Internet Banking, Information Technology (IT), Intention to Adopt, Technology Acceptance Model (TAM), Trust

\section{INTRODUCTION}

Advances in information and communication technologies in particular, the growing use of the internet for business transaction, have had a profound effect on every industry. While this is a global phenomenon, creating a truly global marketplace, penetration of digital transaction services into less developed countries lags behind that of the developed Western countries. While poor economies, 
education and infrastructure are obvious factors in the slow adoption of technology in some developing countries, there are probably also other issues like Trust that plays role.

The spatial and temporal separation of e-commerce between customers and vendors as well as the unpredictability of the Internet infrastructure generate an implicit uncertainty around the initial adoption of on-line service [1]. As technology acceptance model (TAM) is mainly proposed for technology-based perspective through two system features of perceived usefulness (PU) and perceived ease of use (PEOU) [2], it is incomplete in the context of on-line services. Theory of planned behaviour (TPB) is the model widely used in predicting and explaining human behaviour while also considering the roles of individual organizational members and social system in this process [3]. Accordingly, the three influencers in this theory, i.e. attitude, subjective norm and perceived behavioural control, can be interpreted as attitude for technology role, subjective norm for organizational members and social system roles, and perceived behavioural control for individual role.

As a result, an extension of Trust and TAM model with TPB including subjective norm and perceived behavioural control should be in a more comprehensive manner to examine the acceptance of digital transaction. In this extension, trust is placed as an important antecedent of attitude, subjective norm, and perceived behavioural control and also intention. Hopefully, this will provide us more information to overcome the hindrances to adoption of digital transaction systems.

Nepal is a small economy of which the banking era has not yet completed a century. 1937 was the year when first bank established in Nepal. Till 1984, there were only four banks (two commercial banks and two development banks) in Nepal, all state-owned. With the partial opening up of the economy in 1984, the first joint-venture bank was established. Presently, there are 23 commercial banks, 36 development banks and 91 finance companies.

The forms of digital transaction in Nepal include Credit Cards (introduced by Nabil Bank in 1990), Debit Cards (all commercial banks), Automated teller machines (introduced by Himalayan Bank Ltd. in 1995), Electronic fund transfer at points of sale (EFTPOS), Internet banking (introduced by Kumari Bank Ltd. in 2002), Mobile banking; (introduced by Laxmi Bank Ltd. in 2004) [4]. Apart from the banks F1 soft (e-Sewa, Fone Pay), Paybill, i-Pay and a few other companies are acting as intermediaries in the digital transaction system. Despite the introduction of so many alternatives for transactions, Cash still remains the most popular retail payment instrument. In the technologically developed world, IT adoption is faced by barriers, such as the lack of top management support, poor quality IS design and inadequately motivated and capable users [5]. In the developing world, the same barriers appear to be often impenetrable. In addition, problems found in developing counties are attributed to a lack of national infrastructure, capital resources, or government policies set in place to prevent technology transfer [6]. The trust effect in the model is indirect and fully mediated through Attitude, Perceived behavioural control, Subjective norms. There is, however, empirical evidence of the trust direct effect on behaviour intention. The research tests the relationships between the entire variable in the model. 


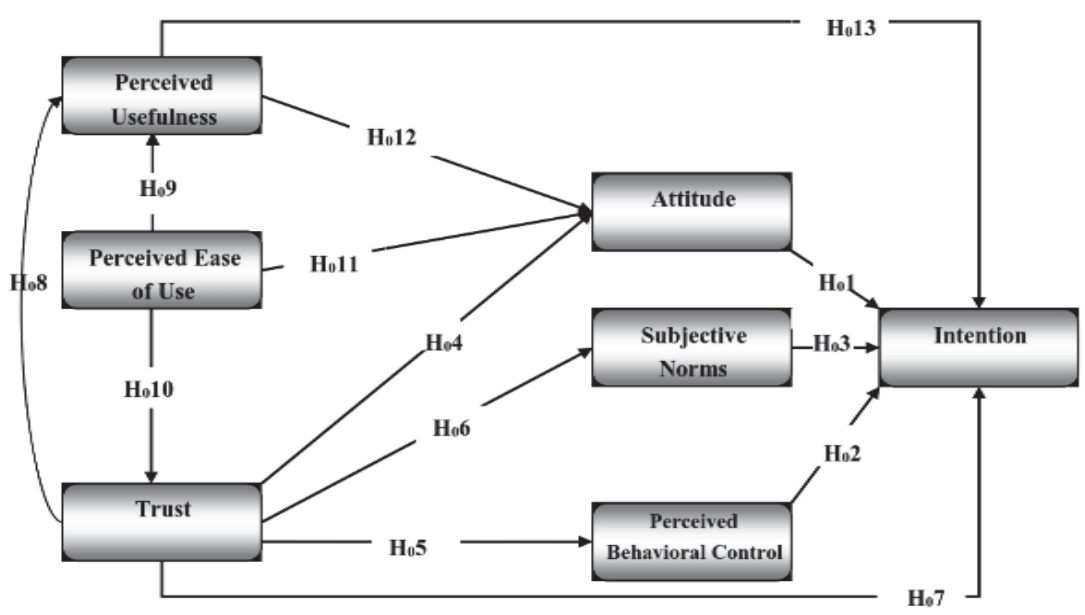

Figure 1 Research Framework [7]

\section{MATERIALS AND METHODS}

This research is quantitative in nature as it explores relationship between variables that influence the use of digital transaction system. More importantly the research will look forward to identifying the relation digital transaction system use with perceived ease of use, perceived usefulness, perceived enjoyment, Information of digital transaction, security and privacy and Quality of Internet connection in context of Nepal.

The population of the study was the households of Kathmandu Metropolitan City with a household population of 671,846 (2001) people. Primary sampling unit was selected so that it covers at least $20 \%$ of the geographic area, the Primary Sampling Unit would be around 8 wards. Then 20 households from each ward was selected by convenient techniques from each ward which making in the total of 160 samples in total.

The questionnaire consisting of two sections i.e. demographic information and an opinion section consisting of statements to be rated in a five point "Likert Scale" was administered to collect the responses.

Following table presents constructs and their corresponding measurements sources used for questionnaire. 
Table 1 Measurement of Constructs

\begin{tabular}{|c|c|c|}
\hline Construct & Factors & Measurement \\
\hline \multirow[t]{3}{*}{ Intention (INT) } & INT1 & \multirow{7}{*}{ Five Point Likert Scale } \\
\hline & INT2 & \\
\hline & INT3 & \\
\hline \multirow[t]{2}{*}{ Attitude (ATT) } & ATT1 & \\
\hline & ATT2 & \\
\hline \multirow[t]{2}{*}{ Perceived Behavioural Control (PBC) } & $\mathrm{PBC} 1$ & \\
\hline & $\mathrm{PBC} 2$ & \\
\hline \multirow{3}{*}{$\begin{array}{l}\text { Trust } \\
\text { (Trust) }\end{array}$} & $\mathrm{T} 1$ & \multirow{13}{*}{ Five Point Likert Scale } \\
\hline & $\mathrm{T} 2$ & \\
\hline & $\mathrm{T} 3$ & \\
\hline \multirow[t]{3}{*}{ Perceived Usefulness (PU) } & PU1 & \\
\hline & PU2 & \\
\hline & PU3 & \\
\hline \multirow[t]{4}{*}{ Perceived ease of use (PEU) } & PEU1 & \\
\hline & PEU2 & \\
\hline & PEU3 & \\
\hline & PEU4 & \\
\hline \multirow[t]{3}{*}{ Subjective Norms (SN) } & SN1 & \\
\hline & SN2 & \\
\hline & SN3 & \\
\hline
\end{tabular}

For validity, questionnaire were reviewed with the help of expert's opinions and suggestions. For reliability, the researcher will administer the question personally to each respondent so that there was no inconsistency in answering the question. If degree of variance is excessively large, the research was investigated for reliability. Internal consistency reliability were also tested using Cronbach's $\alpha$. 
Table 2 Reliability of Constructs

\begin{tabular}{|c|c|c|c|}
\hline Construct & Factors & Cronbach's $\alpha$ & Reliability \\
\hline \multirow{3}{*}{ Intention } & INT1 & \multirow{3}{*}{0.898} & \multirow{3}{*}{ Reliable } \\
\hline & INT2 & & \\
\hline & INT3 & & \\
\hline \multirow{2}{*}{ Attitude } & ATT1 & \multirow{2}{*}{0.743} & \multirow{2}{*}{ Reliable } \\
\hline & ATT2 & & \\
\hline \multirow{2}{*}{ Perceived Behavioural Control } & PBC1 & \multirow{2}{*}{0.393} & \multirow{2}{*}{ Not Reliable } \\
\hline & $\mathrm{PBC} 2$ & & \\
\hline \multirow{3}{*}{ Trust } & $\mathrm{T} 1$ & \multirow{3}{*}{0.912} & \multirow{3}{*}{ Reliable } \\
\hline & $\mathrm{T} 2$ & & \\
\hline & $\mathrm{T} 3$ & & \\
\hline \multirow{3}{*}{ Perceived Usefulness } & PU1 & \multirow{3}{*}{0.801} & \multirow{3}{*}{ Reliable } \\
\hline & PU2 & & \\
\hline & PU3 & & \\
\hline \multirow{4}{*}{ Perceived ease of use } & PEU1 & \multirow{4}{*}{0.841} & \multirow{4}{*}{ Reliable } \\
\hline & PEU2 & & \\
\hline & PEU3 & & \\
\hline & PEU4 & & \\
\hline \multirow{3}{*}{ Subjective Norms } & SN1 & \multirow{3}{*}{0.742} & \multirow{3}{*}{ Reliable } \\
\hline & SN2 & & \\
\hline & SN3 & & \\
\hline
\end{tabular}

\section{RESULTS}

All the 142 respondents of the questionnaire were non-user or at least one time user of digital transaction services. The following table represents the demographic characteristics of the respondents. 
Table 3 Profile of the Respondents

\begin{tabular}{|l|l|l|l|}
\hline Variable & Classification of variable & Frequency & Percent \\
\hline \multirow{3}{*}{ Gender } & Male & 117 & 82.4 \\
\cline { 2 - 4 } & Female & 25 & 17.6 \\
\hline \multirow{3}{*}{ Education } & $21-30$ years old & 123 & 86.6 \\
\cline { 2 - 4 } & $31-40$ years old & 19 & 13.4 \\
\hline \multirow{5}{*}{ Occupation } & Bachelors & 67 & 47.2 \\
\cline { 2 - 4 } & Masters or more & 75 & 52.8 \\
\hline \multirow{3}{*}{ Income Per Month } & Student & 37 & 26.1 \\
\cline { 2 - 4 } & Government Service & 18 & 12.7 \\
\cline { 2 - 4 } & Private Sector & 82 & 57.7 \\
\cline { 2 - 4 } & Others & 5 & 3.5 \\
\hline & Less than 15,000 & 32 & 22.5 \\
\cline { 2 - 4 } & $15,001-30,000$ & 31 & 21.8 \\
\cline { 2 - 4 } & $30,001-45,000$ & 43 & 30.3 \\
\hline & $45,001-60,000$ & 24 & 16.9 \\
\cline { 2 - 4 } & $60,000+$ & 12 & 8.5 \\
\hline
\end{tabular}

The result shows that most of the respondents are male (82.4\%) and between 21-30 years old (86.6\%), $52.8 \%$ have master's degree or more and income of $30.3 \%$ is $31,000-45,000$ per month.

For the purpose of this study, correlation analysis was done to assess the impact that movements or variations in perceived ease of use, perceived usefulness could have on digital transaction use. 
Table 4: Correlation between constructs

\begin{tabular}{|c|c|c|c|c|c|c|c|}
\hline \multicolumn{7}{|c|}{ Correlations } \\
\hline & INT & ATT & PBC & Trust & PU & PEU & SN \\
\hline INT & 1 & $.657^{* *}$ & $.541^{* *}$ & $.458^{* *}$ & $.590^{* *}$ & $.618^{* *}$ & .081 \\
\hline ATT & & 1 & $.503^{* *}$ & $.486^{* *}$ & $.584^{* *}$ & $.468^{* *}$ & $.132^{+}$ \\
\hline PBC & & & 1 & $.268^{* *}$ & $.269^{* *}$ & $.410^{* *}$ & $.210^{*}$ \\
\hline Trust & & & & 1 & $.332^{* *}$ & $.498^{* *}$ & $.379^{* *}$ \\
\hline PU & & & & 1 & $.604^{* *}$ & $.159^{+}$ \\
\hline PEU & & & & & & 1 & $.194^{*}$ \\
\hline SN & & & & & & 1 \\
\hline **. Correlation is significant at the 0.01 level (2-tailed). & & \\
\hline
\end{tabular}

We have used simple linear regression as the model to predict the relationship between the variables. Linear regression is an approach for modelling the relationship between a scalar dependent variable $y$ and one or more explanatory variables (or independent variables) denoted $\mathrm{X}$. The case of one explanatory variable is called simple linear regression. [7]

The following table represents the result of testing the structural links of research model using linear regression analysis. The estimated path coefficients are given along with the associated t-value. Most of the coefficients are significant at the $99 \%$ significance level providing strong support for all the hypothesized relationships. 
Table 5: Relationship between constructs

\begin{tabular}{|c|c|c|c|c|c|c|}
\hline $\begin{array}{r}\text { Hypothesis } \\
\text { (Hoi) }\end{array}$ & Effects & $\mathbf{R}^{2}$ & $\begin{array}{r}\text { Constant } \\
\left(\boldsymbol{\beta}_{0}\right) \\
\end{array}$ & $\begin{array}{r}\text { Coefficient } \\
\left(\boldsymbol{\beta}_{\mathbf{i}}\right) \\
\end{array}$ & t-stat & Remarks \\
\hline $\mathrm{H}_{0} 1$ & $\mathrm{ATT} \rightarrow \mathrm{INT}$ & 0.431 & 0.076 & 0.657 & 10.305 & Reject \\
\hline $\mathrm{H}_{0} 2$ & $\mathrm{PBC} \rightarrow \mathrm{INT}$ & 0.293 & 1.627 & 0.315 & 7.616 & Reject \\
\hline $\mathrm{H}_{0} 3$ & $\mathrm{SN}_{\rightarrow}$ INT & 0.007 & 3.895 & 0.081 & 0.958 & Accept \\
\hline $\mathrm{H}_{0} 4$ & Trust $\rightarrow$ ATT & 0.236 & 3.509 & 0.486 & 6.581 & Reject \\
\hline $\mathrm{H}_{0} 5$ & Trust $_{\rightarrow} \mathrm{PBC}$ & 0.072 & 3.564 & 0.268 & 3.286 & Reject \\
\hline $\mathrm{H}_{0} 6$ & Trust $_{\rightarrow} \mathrm{SN}$ & 0.144 & 2.624 & 0.379 & 4.849 & Reject \\
\hline $\mathrm{H}_{0} 7$ & Trust $\rightarrow$ INT & 0.210 & 2.897 & 0.458 & 6.098 & Reject \\
\hline $\mathrm{H}_{0} 8$ & Trust $\rightarrow$ PU & 0.110 & 3.759 & 0.332 & 4.163 & Reject \\
\hline $\mathrm{H}_{0} 9$ & $\mathrm{PEU}_{\rightarrow} \mathrm{PU}$ & 0.365 & 2.775 & 0.604 & 8.978 & Reject \\
\hline $\mathrm{H}_{0} 10$ & PEU $_{\rightarrow}$ Trust & 0.248 & 1.289 & 0.498 & 6.795 & Reject \\
\hline $\mathrm{H}_{0} 11$ & $\mathrm{PEU}_{\rightarrow} \mathrm{ATT}$ & 0.219 & 3.269 & 0.468 & 6.260 & Reject \\
\hline $\mathrm{H}_{0} 12$ & $\mathrm{PU} \rightarrow \mathrm{ATT}$ & 0.341 & 2.081 & 0.584 & 8.509 & Reject \\
\hline $\mathrm{H}_{0} 13$ & $\mathrm{PU}_{\rightarrow} \mathrm{INT}$ & 0.348 & 0.796 & 0.590 & 8.643 & Reject \\
\hline
\end{tabular}

The results shows that the intention to use e- payment is predicted by Attitude $\left(\beta_{1}=0.657, p<0.01\right)$, Perceived Behavioural Control $\left(\beta_{2}=0.315, \mathrm{p}<0.01\right)$ Trust $\left(\beta_{7}=0.213, \mathrm{p}<0.01\right)$ and Perceived Usefulness $\left(\beta_{13}=0.328, p<0.01\right)$. Attitude is predicted by Trust $\left(\beta_{4}=0.318, \mathrm{p}<0.01\right)$, and Perceived Usefulness $\left(\beta_{12}=\right.$ $0.459, \mathrm{p}<0.01)$. Perceived Usefulness is predicted by Perceived Ease of Use $\left(\beta_{9}=0.584, \mathrm{p}<0.01\right)$. Trust is predicted by Perceived Ease of Use $\left(\beta_{10}=0.498, \mathrm{p}<0.01\right)$. Trust has positive effect on Perceived Behavioural Control $\left(\beta_{5}=0.268, \mathrm{p}<0.01\right)$, Subjective Norms $\left(\beta_{6}=0.379, \mathrm{p}<0.01\right)$ 


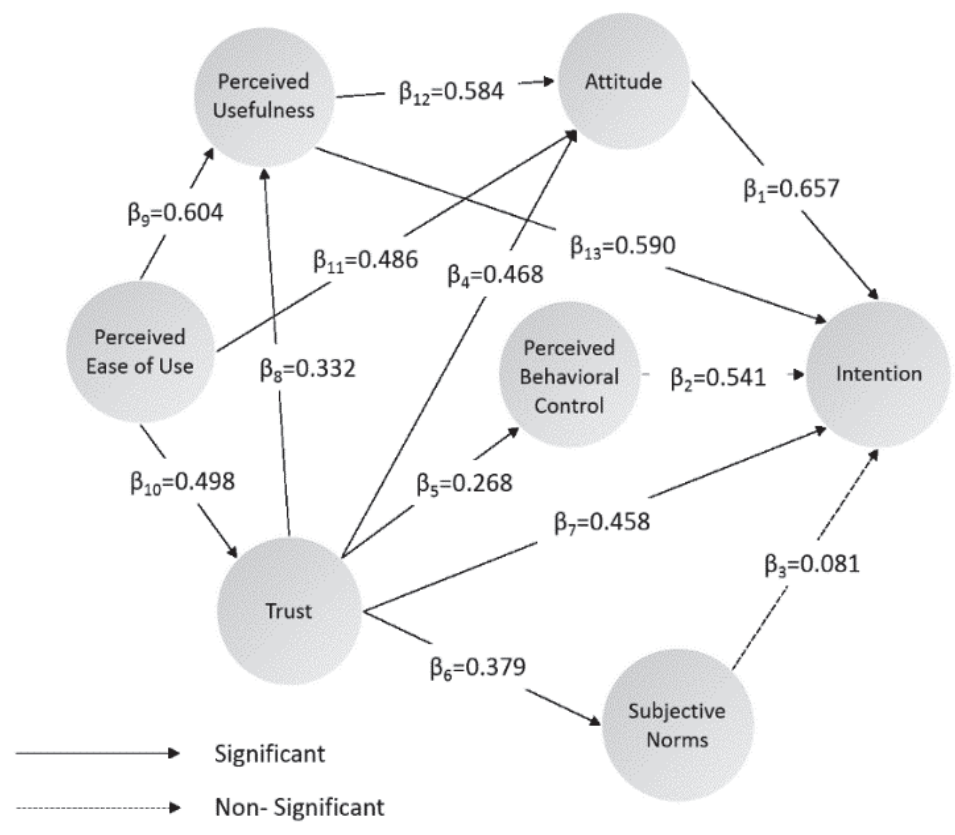

Figure 2: Results of the study

\section{DISCUSSION}

This study shows that both technological and trust-based issues are important in increasing customer's behavioural intention to use digital transaction. The TAM beliefs, Perceived Usefulness and Perceived Ease of Use, and trust are shown to be two sets of underlying antecedents in determining behavioural intention to use, each contributing its significant influence on behavioural intention to use through a number of mediators such as attitude, perceived behavioural control, and subjective norm. This means that to effectively attract customers to use digital transaction, the design of digital transaction site needs to carefully pay attention to both aspects. Besides, as discussed previously, novice users tend to rely more on trust in non-technology features than on Perceived Ease of Use and usefulness in technologybased features to develop their attitude toward the behaviour. In other words, trust is important in determining user's attitude like Perceived Ease of Use and usefulness in digital transaction. The major trust based concerns may include privacy protection, accuracy to declaration, and unauthorized access and so on.

\section{CONCLUSION}

The implication of these findings and conclusions are that, digital transaction service provider need to play a leading role in influencing the perception, and there by the attitude and behaviour of current and potential digital transaction users. The outcome of this study has two practical implication for banks and digital transaction service providers for improving the use and acceptance of these services. 
Awareness of digital transaction services is essential in the early adoption stages of the user. As digital transaction services are still new in Nepal, effective presentations using all forms of media advertising such as leaflets, brochures, web pages, etc., will be useful to introduce the services to a wider audience and educate potential customers about the benefits of digital transaction. To access more potential adopters, information about digital transaction should be provided by bank tellers and bank assistants at branches and by service intermediaries at their counters. The information should include references to "time saving", "convenience" at anywhere any time, "low costs", and "information availability".

\section{ACKNOWLEDGMENTS}

We would like to express gratefulness to Mr Ashish Gajurel for his great perspectives, guidance, support and suggestion. I would also like to thank Dr. Ram Kumar Phuyal and Mr Prabhat Uprety for their suggestions and guidance in conducting an efficient research and analysis. Also thanks goes to the whole Department of Industrial Engineering Team for motivation and support in course of this research.

\section{REFERENCES}

[1] P. A. Pvlou, "Consumer Intentions to adopt Electronic Commerce - Incorporating Trust and Risk in the Technology Acceptance Model.," DIGIT Workshop, pp. 1-28, 2001.

[2] F. D. Davis, R. P. Bagozzi and P. R. Warshaw, "User acceptance of computer technology: A comparison of two theoretical models.," Management Science, vol. 35, no. 8, pp. 982-1003, 1989.

[3] I. Aizen, "The Theory of Planned Behavior.," in Organizational Behavior and Human Decision Processes., 1991, pp. 197-221.

[4] B. B. Mishra, "The Development of E-Payment and Challenges in Nepal.," in The Development of E-payments and Challenges for Central Banks, Kuala Lumpur, Malaysia, 2008.

[5] T. H. Kwon and R. W. Zmud, "Unifying the fragmented models of information systems implementation.," in Critical Issues in Information Systems Research., 1987, pp. 227-252.

[6] S. E. Goodman and J. D. Green, "Computing in the Middle East.," Communication of ACM, vol. 35 , no. 8, pp. 21-25, 1992.

[7] A. F. D, Statstical Model: Theory and Practice, Cambridge, U.K.: Cambridge University Press, 2009.

[8] S. N. Baraghani, "Factors Influencing the Adoption of Internet Banking," Luleå University of Technology, Luleå, Sweden, 2007. 